\title{
Os deslocamentos da criança no interior do reformulável e sua constituição subjetiva na aquisição da escrita: um olhar pecheutiano
}

\author{
Child's displacements within the realm of what can be \\ reformuled and his/her subjective constitution in the \\ writing acquisition: a Pecheutian perspective
}

\author{
Giovane Fernandes Oliveira*
}

\begin{abstract}
RESUMO: Este artigo analisa sequências discursivas (SDs) de aquisição da escrita à luz da análise do discurso peucheutiana, bem como das reflexões de Indursky (2016) sobre as determinações discursivas da escrita e de Zapelini (2016) sobre a escrita de entremeio. O corpus analítico envolve duas SDs de um menino acompanhado longitudinalmente em sua relação inicial com a escrita. Conclui-se que a aquisição da escrita não se reduz a um processo cognitivo de aprendizagem ou a um processo sociointeracional de uso da língua: trata-se de um processo de transformação simbólica sem início nem fim, pois o sujeito muda sua relação com o escrito a cada nova diferente formação discursiva (FD) em que se insere e mesmo no interior de uma única FD.
\end{abstract}

PALAVRAS-CHAVE: discurso; enunciação; constituição subjetiva; aquisição da escrita.

\begin{abstract}
This article analyzes discursive sequences (SDs, in the Portuguese text) of writing acquisition through Pecheutian Discourse Analysis, as well as Indursky's reflections (2016) about the writing discursive determinations and Zapelini's ones (2016) about the intersperse written. The analytical corpus consists of two SDs of a boy longitudinally assisted in his initial relationship with writing. The paper concludes that the writing acquisition is not reduced to a cognitive learning process or a social interactional process of language use: it is a symbolic transformation process without beginning or end, since the subject changes his/her relationship with writing with each new different discursive formation (FD, in the Portuguese text) in which the subject inserts himself/herself and even within a single FD.
\end{abstract}

KEYWORDS: discourse; enunciation; subjective constitution; writing acquisition.

\footnotetext{
* Doutorando em Estudos da Linguagem pelo Programa de Pós-Graduação em Letras (PPGLetras) da Universidade Federal do Rio Grande do Sul (UFRGS), Bolsista de Doutorado da Coordenação de Aperfeiçoamento de Pessoal de Nível Superior (CAPES), gio.ufrgs@gmail.com, https://orcid.org/0000-0001-8251-8353.
} 


\begin{abstract}
Uma vez transformados pela escrita em alguém que pode ler ou escrever, não é possível subtrairmo-nos a seu efeito, nem concebermos qual é a relação que aquele que não sabe ler tem com esses sinais que, para nós, apresentam-se como transparentes. Mas de que modo se opera essa transformação de/em alguém que passa a ver o que não via e é assim capturado pela escrita enquanto funcionamento simbólico?
\end{abstract}

Cláudia de Lemos

\title{
1 Um recorte temático
}

Renomada linguista brasileira no campo da aquisição da fala, em que inaugurou, a partir da linguística saussuriana e da psicanálise lacaniana, uma perspectiva teórica para explicar como a criança se constitui sujeito falante, Claudia de Lemos (2009) reflete sobre a aquisição da escrita em texto no qual consta a epígrafe acima.

Nesse texto, a linguagem/língua é concebida pela autora não como um sistema representacional ou uma atividade interativa, mas como um objeto que é efeito de seu próprio funcionamento simbólico. Já o sujeito que se relaciona com tal objeto é visto como uma posição discursiva produzida por esse mesmo funcionamento simbólico, e não como um sujeito cognoscente ou um indivíduo empírico. Por sua vez, a escrita é compreendida não como um objeto de conhecimento ou uma forma de representação da linguagem/língua, e sim como uma prática linguístico-discursiva transformadora do sujeito. Finalmente, a aquisição da escrita é entendida como um processo irreversível de transformação pelo simbólico - e não como a aquisição de um saber que se estabiliza após um dado estágio cognitivo ou somente como um processo de mudança da relação interacional sujeito/linguagem.

A partir dessas concepções, De Lemos (2009) distancia-se das abordagens cognitivistas e sociointeracionistas predominantes no campo aquisicional, deslocando a ênfase da aprendizagem da escrita para a constituição subjetiva da criança ao aceder à condição de escrevente. Outra diferença relevante da perspectiva da linguista quanto às abordagens cognitivistas e sociointeracionistas 
diz respeito ao papel do outro, tomado não como um mero provedor de input ou apenas como um interlocutor fisicamente presente ou representado que exerce uma função mediadora ou facilitativa nesse processo, mas como uma instância representativa da língua em sua manifestação escrita e um intérprete que reconhece como significante a escrita da criança, introduzindo-a no mundo letrado. A autora observa, contudo, que "essa interpretação não tem origem no adulto mas no discurso em que ele próprio, submetido ao funcionamento lingüístico-discursivo [sic], é significado" (DE LEMOS, 2009, p. 27), o que a leva a sugerir que "A Análise do Discurso da linha francesa e a psicanálise são os espaços de teorização que permitiriam desenvolver esse e outros aspectos dos processos de identificação envolvidos nesse funcionamento [o da escrita em aquisição]” (DE LEMOS, 2009, p. 27)

Provocado por tal sugestão da autora, tenho por objetivo, neste artigo, apresentar uma possibilidade de análise de sequências discursivas de aquisição da escrita a partir da perspectiva teórica do filósofo francês Michel Pêcheux ${ }^{68}$.

Inaugurada em 1969, com o livro Análise Automática do Discurso (doravante, $A A D-69$ ), resultado da tese de doutoramento de Pêcheux, a perspectiva discursiva pecheutiana foi submetida, por seu fundador, a transformações e deslocamentos teórico-metodológicos até 1983, ano de seu falecimento. A análise do discurso iniciada pelo autor (doravante, AD) perdeu força na França após sua morte, com a dispersão do grupo de pesquisadores que se reunia em seu entorno ( $c f$. MALDIDIER, 2003), e conheceu avanços significativos no Brasil, com os trabalhos de Eni Orlandi e de estudiosos alinhados teoricamente à autora.

Devido aos limites deste artigo e à sua natureza mais teórico-analítica do que epistemológica, restringir-me-ei, aqui, aos seguintes textos de Pêcheux: o já

\footnotetext{
${ }^{68}$ Não desconheço a existência de estudos que, filiados à perspectiva linguístico-psicanalítica de Claudia de Lemos, debruçam-se sobre a teorização e a análise da relação criança-escrita. Dentre tais estudos, destacam-se o de Borges (2006) e o de Bosco (2006). Entretanto, no artigo ora apresentado, sigo na direção apontada por De Lemos (2009) de uma interface entre os estudos de aquisição da escrita e os estudos discursivos peucheutianos. Ainda assim, como o leitor verá na seção analítica, dialogarei com algumas ideias de Bosco (2006) sobre a relação entre a escrita inicial e o nome próprio.
} 
referido livro $A A D-69$, o artigo de 1971 intitulado Língua, "linguagens", discurso (2015) e os trabalhos, ambos de 1975, A propósito da análise automática do discurso: atualização e perspectivas (2014)69 e Semântica e discurso: uma crítica à afirmação do óbvio (2014). Trata-se, então, de uma reflexão ancorada nas duas "épocas” iniciais da AD (1969-1975), das três delineadas por Pêcheux (2014).

Além desse recorte teórico macro na obra pecheutiana, opero ainda um recorte teórico micro no interior dos textos selecionados, neles focalizando as seguintes noções centrais: formação discursiva, interdiscurso, intradiscurso, língua, enunciação e discurso. Em torno destas, gravitam noções-satélite, como formação ideológica, esquecimento $n^{o} 1$, esquecimento $n^{o} 2$, condições de produção, pré-construído e discurso transverso ${ }^{70}$.

Às reflexões de Pêcheux, recuperadas na primeira parte da seção 2 (cf. 2.1), alio as reflexões de duas autoras brasileiras, Freda Indursky e Clésia da Silva Mendes Zapelini, que deslocam as ideias do filósofo para teorizarem, respectivamente, sobre a escrita (cf. 2.2) e sobre a aquisição da escrita (cf. 2.3). Após o recorte teórico da seção 2, procedo, na seção 3, a um recorte analítico, esboçando uma análise de sequências discursivas de aquisição da escrita, e, na seção 4, formulo algumas considerações sobre o trajeto percorrido.

\footnotetext{
69 Embora esse artigo do número 37 de Langages tenha sido escrito em coautoria com a linguista Catherine Fuchs, referir-me-ei, no corpo do texto, a Pêcheux, pois privilegiarei a primeira parte do artigo - mais teórica -, que Maldidier (2003) atribui ao filósofo, do que se pode inferir que a segunda parte - mais técnica - ficou a cargo da linguista. Entretanto, após as citações diretas, nas referências entre parênteses, ambos os autores serão mencionados.

$7^{70}$ Como já dito, Pêcheux efetuou modificações conceituais e procedimentais em sua perspectiva discursiva, de modo que as noções acima mencionadas recebem diferentes formulações no curso de suas elaborações teóricas. No entanto, uma vez que mapear as mudanças às quais foram submetidas tais noções extrapola os limites do presente estudo, circunscrevo a abordagem deste às formulações que mais contribuem à problematização do tema aqui eleito para investigação: a aquisição da escrita.
} 


\section{Um recorte teórico}

2.1 Formação discursiva, interdiscurso, intradiscurso, língua, enunciação e discurso

Noção tomada de empréstimo de Michel Foucault e ressignificada teoricamente por Jean-Jacques Courtine e Michel Pêcheux, a formação discursiva (FD) é concebida por estes como a representação, na linguagem, de uma formação ideológica (FI) - posição numa dada formação social caracterizada pela luta de classes. A FD determina o que pode e deve ser dito em dada situação e, assim, interpela os indivíduos em sujeitos do seu discurso. Para Pêcheux, o sentido das palavras/expressões/proposições produz-se no interior de uma FD, mas apresenta um caráter opaco devido a sua dependência em relação ao interdiscurso enquanto exterioridade constitutiva das FDs, caracterizado pelo "fato de que 'algo fala' (ça parle) sempre 'antes, em outro lugar e independentemente', isto é, sob a dominação das formações ideológicas” (PÊCHEUX, 2014, p. 151, aspas e itálicos do autor).

Tal dependência ocorre, de uma parte, pela evidência do sujeito como causa e origem de si (esquecimento $\mathrm{n}^{0} 1$, ideológico-inconsciente) e, de outra parte, pela evidência do sentido como literal e transparente (esquecimento $\mathrm{n}^{\circ} 2$, enunciativo). Esse duplo efeito de evidência deve-se ao fato de que a FD simula o interdiscurso no intradiscurso enquanto "funcionamento do discurso com relação a si mesmo", encadeando "o que eu digo agora, com relação ao que eu disse antes e ao que eu direi depois; portanto, o conjunto de fenômenos de 'coreferência' que garantem aquilo que se pode chamar o 'fio do discurso"' (PÊCHEUX, 2014, p. 151, aspas e itálicos do autor).

Logo, na base dos esquecimentos ideológico-inconsciente e enunciativo, está a simulação, pela FD, do interdiscurso no intradiscurso enquanto fio do discurso do sujeito. Segundo Pêcheux, o intradiscurso é estruturado a partir do 
encadeamento de pré-construídos (já ditos provenientes de discursos anteriores, mas ignorados em sua procedência e considerados portadores de um sentido cristalizado) por meio do discurso transverso (processo de articulação de enunciados que atravessa e conecta os pré-construídos no fio discursivo). Acrescenta o autor que a forma-sujeito, pela qual o sujeito do discurso identificase à FD que o constitui, incorpora e dissimula os elementos interdiscursivos pré-construídos e discursos transversos -, fazendo o intradiscurso parecer uma interioridade não determinada por uma exterioridade e fundando a unidade imaginária do sujeito, a qual o faz esquecer-se daquilo que o determina, em um efeito idealista de autonomia.

Já a língua é tomada por Pêcheux como a base material sobre a qual se realizam os processos discursivos, entendidos como o funcionamento da língua em relação a representações postas em jogo nas relações sociais. Conforme o filósofo, a base linguística funcionando em relação a ela própria comporta, de um lado, o léxico enquanto conjunto estruturado de elementos articulados sobre a sintaxe e, de outro lado, a sintaxe enquanto modo de organização dos traços das referências enunciativas.

A enunciação, por sua vez, é assumida por Pêcheux como o conjunto de mecanismos internos à base linguística que articulam sobre ela os processos discursivos, delimitando as fronteiras entre o dito/selecionado e o não dito/rejeitado. De acordo com o estudioso, além de possibilitar a tomada de posição do sujeito quanto às representações postas em jogo nas relações sociais, a enunciação é também um "espaço imaginário que assegura ao sujeito falante seus deslocamentos no interior do reformulável de forma que ele faça incessantes retornos sobre o que formula" (PÊCHEUX; FUCHS, 2014, p. 178, itálicos dos autores). Tais deslocamentos enunciativos consistem em retornos do sujeito sobre o seu discurso, antecipações do efeito deste, tentativas de explicitação ou reformulação do seu dizer. A enunciação acoberta, para o sujeito identificado a uma FD, a exterioridade constitutiva desta, fazendo-o esquecer-se daquilo que o determina, como se fosse um interior sem exterior (esquecimento 
$n^{0} 1$ ), e fazendo-o esquecer-se de que há outros sentidos possíveis, como se a significação fosse transparente e naturalizada (esquecimento $\mathrm{n}^{0} 2$ ).

Finalmente, o discurso é definido por Pêcheux não como "uma transmissão de informação entre $A$ e $B$ mas, de modo mais geral, [como] um “efeito de sentidos' entre os pontos $A$ e $B$ ” (PÊCHEUX, 2014, p. 81, itálicos e aspas dos autores). Esses pontos A e B são compreendidos pelo autor não como organismos humanos individuais, e sim como posições definidas na estrutura de uma formação social enquanto conjuntura caracterizada pelo modo de produção dominante e pelas relações de classe. Em outras palavras, trata-se não de sujeitos empíricos, mas de posições sociais - como os lugares de patrão e operário -, posições representadas nos processos discursivos, mas nestes não refletidas como tais, pois o que funciona neles "é uma série de formações imaginárias que designam o lugar que $A$ e $B$ se atribuem cada um a si e ao outro, a imagem que eles se fazem do seu próprio lugar e do lugar do outro" (PÊCHEUX, 2014, p. 82, itálicos do autor). Também o referente de que falam A e B se trata de "um objeto imaginário (a saber, o ponto de vista do sujeito) e não da realidade física" (PÊCHEUX, 2014, p. 83, itálicos do autor). Logo, assim como os lugares discursivos não consistem em indivíduos de carne e osso, o referente do discurso não consiste numa realidade ontológica existente a priori, mas numa realidade discursivizada a partir das imagens dos interlocutores sobre si, sobre o outro e sobre o que falam.

Tais formações imaginárias são indissociáveis das formações ideológicas e das formações discursivas, como indissociáveis são as relações língua-discurso e interdiscurso-intradiscurso. Essas formações e relações determinam a enunciação do sujeito do discurso em diferentes práticas discursivas, dentre as quais a prática da escrita. Sobre isso, tratam as seções seguintes. 


\title{
2.2 As determinações da prática discursiva da escrita
}

A partir da análise do discurso pecheutiana, Indursky (2016) desenvolve uma profunda e instigante teorização sobre as determinações da prática discursiva da escrita. Segundo a autora, a escrita é uma prática discursiva e, por isso, social e política, realizada por um sujeito interpelado pela ideologia e afetado pelo inconsciente.

Conforme Indursky (2016), a escrita procede a uma retomada de saberes inscritos no interdiscurso, a partir de um trabalho entrecruzado da interpretação, da memória e do esquecimento. Vista como um processo discursivo, a escrita é algo em movimento e, apesar de poder ser suspensa, pausada ou interrompida, não tem um fim, pois pode sempre ser retomada e continuada. A autora defende ainda que o processo de escrita, caracterizado por um efeito de abertura e incompletude, tem como produto o texto, o qual é, ao contrário, caracterizado por um efeito de fechamento e completude. Para Indursky (2016), porém, o texto não passa de uma unidade provisoriamente estruturada, que pode ser desestruturada a qualquer momento por meio de um trabalho de leitura ou de escritura. É na relação entre tais trabalhos que a autora se detém, refletindo sobre

\begin{abstract}
a possibilidade que o sujeito-autor tem de ocupar o lugar discursivo do outro, do leitor, retornando a seu próprio texto para sobre ele fazer uma leitura desestabilizadora de seu efeito de completude, seja para se autocorrigir, seja para trazer outros fios discursivos que, por diversos motivos, não puderam ser contemplados anteriormente e tramá-los àqueles que aí já se encontravam. (INDURSKY, 2016, p. 31, negritos meus).
\end{abstract}

De acordo com Indursky (2016), ao retornar ao seu escrito, o sujeito-autor o transforma no rascunho de um novo texto, abrindo-o novamente ao interdiscurso e se lançando uma vez mais à busca ilusória pela completude e pelo controle de sentidos que insistem em lhe escapar. Como exemplos desse retorno, a autora menciona o trabalho editorial, o trabalho didático, o trabalho acadêmico e o trabalho literário. A estes, eu adicionaria o trabalho realizado pela criança na 
dita aquisição da escrita, do que dá testemunho a sequência discursiva analisada na seção 3, a qual mostra a criança retornando a seu próprio texto - nos termos de Indursky (2016) - ou - nos termos de Pêcheux e Fuchs (2014) - deslocandose no interior do reformulável.

De uma teorização mais geral, Indursky (2016) passa a uma teorização mais específica, esmiuçando as diferentes articulações a partir das quais podem ser observadas as determinações da prática discursiva da escrita. Dentre tais articulações, destacam-se as seguintes:

- A articulação interdiscurso-intradiscurso: conforme a autora, a escrita fornece materialidade linguística a saberes dessintagmatizados e desnivelados que circulam na FD e no interdiscurso e, ao serem conectados no intradiscurso pelo trabalho discursivo do sujeito, promovem, a um só tempo, a atualização de uma memória e o apagamento dos vestígios da exterioridade no interior do texto.

- A articulação língua-ideologia: segundo Indursky (2016), a língua concebida como opaca e sujeita a jogos, falhas e equívocos que podem provocar deslizamentos e derivas de sentidos - viabiliza, por intermédio de uma sintaxe discursiva, a materialização na escrita dos saberes provenientes da FD e do interdiscurso, saberes estes ideológicos porque historicamente determinados.

- A articulação ideologia-cultura: para a pesquisadora, a ideologia materializa-se na escrita, nela imprimindo direções de sentido e efeitos de evidência que interpelam o indivíduo em sujeito de seu discurso escrito. A ideologia regula a interpretação que esse sujeito faz das discursividades e das práticas/dos saberes culturais, sendo a cultura entendida por Indursky (2016) como um aparelho ideológico do Estado que envolve um conjunto de práticas diversificadas, desiguais e não homogêneas. Para a autora, tais práticas culturais integram a memória de um corpo social, inscrevendo-se no interdiscurso e funcionando à moda de uma FD, isto é, o sujeito da escrita tanto pode se identificar com os efeitos de sentido 
produzidos por essas práticas, repetindo-as, quanto pode questioná-las e, até mesmo, resistir-lhes.

- A articulação memória-esquecimento: Indursky (2016) defende que a condição da escrita é a inscrição do sujeito na discursividade, pois ele precisa de uma memória prévia para poder dizer, mas, paradoxalmente, o resgate de discursos e sentidos anteriores deve ser esquecido, abrindo espaço às retomadas (identificações), às reformulações (contraidentificações) e às transformações (desindentificações).

A reflexão teórica da autora sobre as determinações da prática discursiva da escrita pode ser visualizada a partir do seguinte esquema:

Figura 1 - As determinações da prática discursiva da escrita.

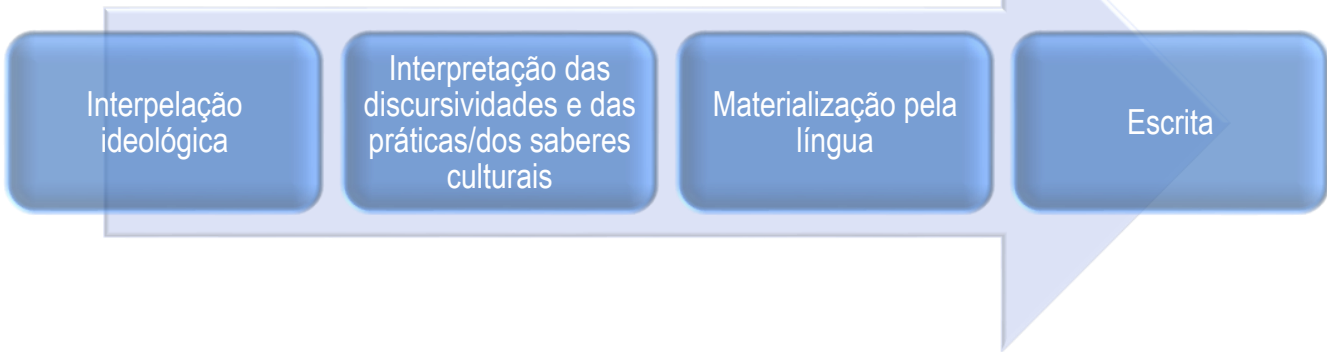

Fonte:: Elaborado pelo autor com base em Indursky (2016).

\subsection{A escrita de entremeio}

Se Indursky (2016) opera um primeiro deslocamento, da teorização mais geral de Pêcheux sobre o discurso para uma teorização mais específica sobre a escrita, Zapelini (2016) opera um segundo deslocamento, ainda mais específico do que o de Indursky (2016), focalizando a aquisição da escrita.

Em estudo sobre a relação de crianças com a escrita antes da alfabetização formal, à luz da $\mathrm{AD}$ pecheutiana, Zapelini (2016) formula a noção de escrita de entremeio. Acompanhando uma turma de Educação Infantil ao longo de um ano, 
a autora identifica quatro funcionamentos discursivos (F1, F2, F3 e F4) que movimentam as produções gráficas infantis antes do Ensino Fundamental I. No cerne de cada funcionamento, a pesquisadora reconhece uma manifestação textual predominante, concebendo texto como um objeto simbólico que estabelece uma unidade de sentido com a situação em que circula (cf. ORLANDI, 2008).

No primeiro funcionamento discursivo (F1), as produções escritas emergem em meio a brincadeiras, de modo que o escrever e o brincar são atividades que acontecem simultaneamente, assim como os sentidos são elaborados em conjunto. Devido à interdependência com a ludicidade e à indefinição das formas gráficas, essas produções do F1 são consideradas por Zapelini (2016) como pré-textos, os quais impulsionam novos sentidos e novos funcionamentos e são representados pela seguinte fórmula: grafia + sentido = pré-texto.

No segundo funcionamento discursivo (F2), as escritas continuam a ser produzidas em situações lúdicas, mas começam a ganhar novas formas e novos sentidos, pois a presença do texto oral acentua-se durante a elaboração coletiva do texto escrito pelas crianças. Essa unidade entre grafia e oralidade em todas as materialidades do F2 resulta no que a pesquisadora denomina texto 1, que recebe a seguinte formulação: grafia + ORAL ${ }^{71}+$ sentido = texto 1 .

No terceiro funcionamento discursivo (F3), a relação entre a ludicidade e a elaboração das produções enfraquece, visto que a criança já distingue o lúdico do escrito e decide quando deseja parar de brincar para elaborar uma produção escrita. A unidade de sentido predominante no F3 é chamada por Zapelini (2016) de texto 2 e assim formulada: GRAFIA + oral + sentido = texto 2.

No quarto funcionamento discursivo ( $\mathrm{F} 4)$, a elaboração das produções distancia-se ainda mais das brincadeiras, e a criança passa a usar a grafia para escrever o que deseja, seja com as palavras que conhece ou com aquelas que o adulto lhe apresenta ao ajudá-la em sua produção. Tal ilusória autonomia

\footnotetext{
${ }^{71}$ Nessa segunda formulação, bem como nas seguintes, Zapelini (2016) grifa em caixa alta o termo que sinaliza o elemento predominante em cada funcionamento discursivo da escrita emergente.
} 
constitui uma unidade de sentido que é denominada pela autora como texto 3 e esquematizada pela seguinte fórmula: grafia + sentido + ESCRITA = texto 3.

A partir da análise das produções infantis recortadas como sequências discursivas e agrupadas nos quatro funcionamentos acima descritos, Zapelini (2016) conclui que os sentidos que movimentam as produções iniciam em um processo de vai e vem entre brincadeiras, conversações e elaborações das produções, as quais são afetadas tanto pelo discurso escolar quanto pelo discurso familiar:

[...] o sujeito-criança enuncia do lugar social de aluno e também está afetado pela FD pedagógica, pois ao escrever as letras no contexto da escola, onde as letras ficam disponíveis no mural, nas paredes, o sujeito já sofre esse assujeitamento e se subjetiva nesse espaço. Esse sujeito também está afetado pelo LD [lugar discursivo] da família, pois seus familiares, objetivando que se efetive a aprendizagem da escrita e da leitura, oferecem para seus filhos livros com letras e álbuns com imagens e letras. Desse modo, segundo Orlandi (2008, p. 103), "o sujeito se submete à lingua(gem) - mergulhado em sua experiência de mundo e determinado pela injunção a dar sentido, a significar(-se). (ZAPELINI, 2016, p. 137).

De acordo com Zapelini (2016), ao ser afetada pelo que a autora designa FD pedagógica, a escrita de entremeio ganha um novo valor simbólico, constituindo-se no encontro entre letras, números e desenhos, os quais formam uma rede de sentidos e possibilitam que a criança aprenda a representar com a língua escrita. Tal encontro é ilustrado pela autora mediante a seguinte figura:

Figura 2 - A constituição da escrita de entremeio. 


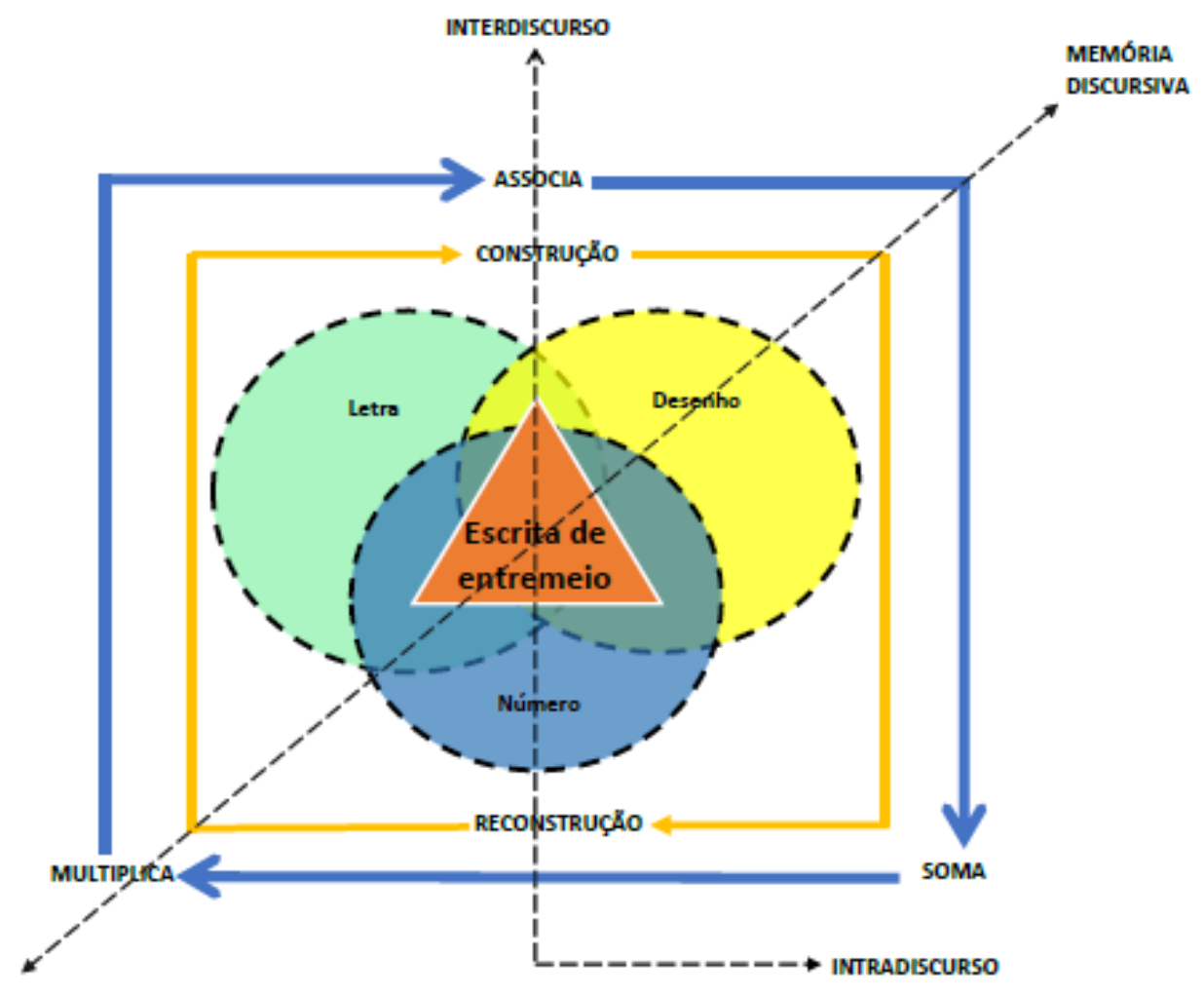

Fonte: ZAPELINI, 2016, p. 138.

Conforme Zapelini (2016), nesse encontro entre letras, números e desenhos, a criança vai significando e criando a sua possibilidade de escrita, construindo e reconstruindo sentidos que oscilam entre a estabilização e a deriva na articulação do interdiscurso com o intradiscurso e a memória discursiva. Trata-se, para a autora, de um processo de autoria, que é marcado pelas condições de produção do espaço escolar e que movimenta sentidos e dizeres a cada novo funcionamento discursivo. Nesse processo, a criança transita da posição sujeito-aluno à forma-sujeito aluno ao identificar-se (não sem momentos de resistência e contraidentificações) à FD pedagógica. 


\section{Um recorte analítico}

As sequências discursivas (SDs) analisadas a seguir fazem parte do corpus de minha pesquisa de doutoramento72, o qual está sendo constituído a partir de coletas naturalísticas (realizadas em ambientes domésticos) e longitudinais (ao longo de dois anos e meio, de uma a duas vezes por mês, em sessões com duração entre trinta minutos e uma hora com cada participante).

Tais coletas são realizadas com duas crianças: uma menina (Helena), que está sendo acompanhada dos três anos e três meses aos cinco anos e nove meses, antes de iniciar a alfabetização formal; e um menino (Emanuel), que está sendo acompanhado dos seis anos e três meses aos oito anos e nove meses, já em processo de alfabetização. Trata-se, pois, do registro de cinco anos iniciais da relação criança-escrita (dois anos e meio pré-alfabetização e dois anos e meio durante o ciclo desta).

A pesquisa foi aprovada pelo Comitê de Ética em Pesquisa da Universidade Federal do Rio Grande do Sul (UFRGS), o qual, inclusive, autorizou o uso e a divulgação do nome próprio dos participantes, devido ao importante papel que este desempenha na aquisição da escrita, ao funcionar como uma porta de entrada da criança na escrita. Neste trabalho, porém, serão analisadas sequências discursivas de somente uma das crianças: Emanuel.

Concebendo, na esteira de Orlandi (2008) e Zapelini (2016), o texto como um objeto simbólico que estabelece uma unidade de sentido com a sua situação de produção e compreensão, entendo a SD selecionada para análise como desdobrada, de um lado, em um plano contextual (que denomino alocução falada) e, de outro lado, em um plano textual (que nomeio enunciado escrito). Esses dois tipos de SD viabilizam uma análise do processo de produção do discurso mais do que uma análise unicamente do produto textual que o materializa.

\footnotetext{
${ }^{72} \mathrm{Em}$ minha pesquisa de doutoramento, busco formular as bases de um diálogo entre a teoria da linguagem de Émile Benveniste e o fenômeno da aquisição da escrita. É, portanto, um referencial teórico distinto deste que aqui mobilizo.
} 
A SD da alocução falada foi transcrita a partir das seguintes notações:

Quadro 1 - Convenções de transcrição.

\begin{tabular}{|c|c|}
\hline Episódio & $\begin{array}{l}\text { Indicação a) da idade da criança no momento da } \\
\text { coleta; b) dos participantes com as três letras iniciais } \\
\text { de seu nome, que aparecem nas trilhas de fala; c) da } \\
\text { situação da coleta. }\end{array}$ \\
\hline Com & 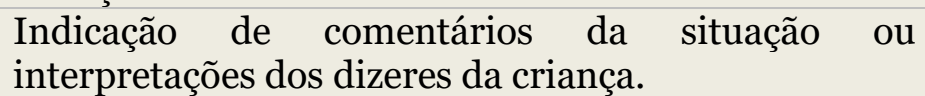 \\
\hline (?) & Indicação de dúvida de transcrição. \\
\hline XXX & $\begin{array}{l}\text { Indicação de palavra ou frase não compreendida pelo } \\
\text { transcritor. }\end{array}$ \\
\hline Sublinhado & Indicação de tom descendente. \\
\hline$\overline{\text { MAIÚSCULAS }}$ & Indicação de tom ascendente. \\
\hline$@$ & Indicação de pausa curta. \\
\hline @@@ & Indicação de pausa longa. \\
\hline$[=]$ & Indicação de eventos não verbais e breves explicações. \\
\hline$[\ldots]$ & $\begin{array}{l}\text { Indicação de segmentos não relevantes suprimidos na } \\
\text { transcrição. }\end{array}$ \\
\hline / & $\begin{array}{l}\text { Indicação de interrupção brusca de alguma palavra ou } \\
\text { frase. }\end{array}$ \\
\hline ? & Indicação de entonação de pergunta. \\
\hline ! & Indicação de entonação de exclamação. \\
\hline ... & Indicação de turno de fala em suspenso. \\
\hline , & $\begin{array}{l}\text { Indicação de organização de turnos de falas longos ou } \\
\text { enumerações. }\end{array}$ \\
\hline
\end{tabular}

Fonte: Elaborado pelo autor com base em Silva (2009).

\section{SD1a - Alocução falada}

Idade da criança:

Participantes:

Situação:

LIA:

EMA:

LIA:

EMA:

LIA:

EMA:

LIA:

Com:

EMA:

LIA:

EMA:
6;07.14.

EMA (criança); GIO (investigador); LIA (sobrinha de 9 anos).

EMA está em sua casa, sentado à mesa da cozinha com GIO e LIA, a qual o ajuda a escrever seu nome.

sooou

sooou

zaaa

zaaa@ooo /

não é junto! é espaço [= olhando para EMA escrevendo]

não

é espaço

EMA nega e volta o olhar para GIO em busca de apoio.

não

é sim

não 
GIO:

Com:

souza olivera é junto?

EMA nega com um meneio de cabeça ao mesmo tempo em que LIA retoma a palavra.

LIA:

EMA:

LIA:

não [= nega com a cabeça $]$

olha @ eu faço junto

eu não

eu sim

o meu nome não é junto

tu gosta de fazê junto?

EMA assente com um gesto de cabeça.

mais ele escreve separado né?

XXX

é souza@ olivera @ a gente fala correndo e parece uma palavra só né @ souzolivera

Com:

$[\ldots]$

GIO:

[...]

GIO:

[...]

GIO:

Com:

GIO faz um gesto cortante com a mão para sinalizar que são duas palavras distintas e depois faz um gesto fluido para sinalizar que essas palavras são pronunciadas como se fossem uma só.

sim souza tava certo @ daí tu dá um espacinho em branco

sim mais o olivera já é otra palavra

tem qui botá um espaço

EMA olha para GIO e volta a escrever, inserindo mais espaços em branco no que está escrevendo.

GIO:

mais espaço@ mais mais mais mais aííi!

\section{SD1b - Enunciado escrito}

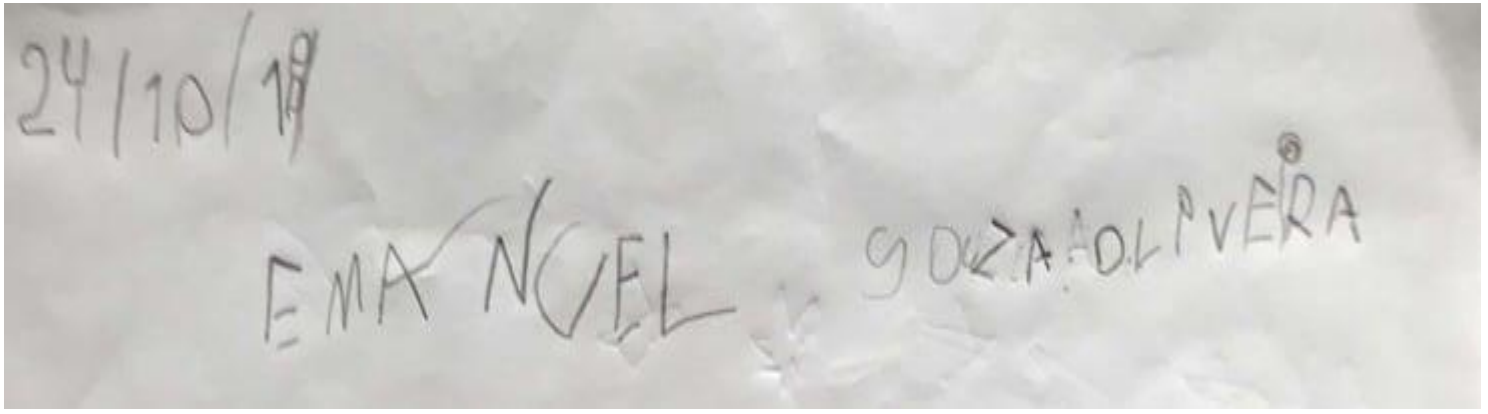

Na SD1a, EMA tenta escrever seus dois sobrenomes ("Souza" e "Oliveira"), mas se depara com a dificuldade de segmentar graficamente o que para ele consiste numa unidade única. Tal dificuldade, contudo, emerge apenas quando o outro (criança) intervém e segue-se um conflito: "não é juntu! é espaçu" / "não" / "é espaçu" / "não" / "é sim" / "não". EMA compreende que LIA lê como inadequada a sua segmentação não convencional, no entanto discorda dessa leitura. Essa discordância deve-se ao fato de EMA ter uma escuta igualmente 
distinta da de LIA: ele ouve seus dois sobrenomes como integrados numa só unidade fônica e reproduz essa escuta em sua escrita, hipossegmentando as duas unidades gráficas numa única ("Souzaoliveira”).

O interessante é que, ao negar a asserção de LIA, EMA volta seu olhar para GIO em busca de apoio, como se a anuência do outro (adulto), a quem parece atribuir a imagem de instância legitimadora da escrita convencional na situação discursiva, pudesse reconhecer como legítima a sua produção gráfica. Todavia, em face do desacordo também de GIO, expresso em "mais o olivera já é otra palavra” / "tem que botá um espaço” / “mais espaço @ mais mais mais mais aíí!!", EMA retorna sobre o seu escrito e o reformula, inserindo espaço entre "Souza" e “Oliveira”, como podemos ver na SD1b.

A enunciação atua, aqui, como "espaço imaginário que assegura ao sujeito falante [escrevente] seus deslocamentos no interior do reformulável de forma que ele faça incessantes retornos sobre o que formula” (PÊCHEUX; FUCHS, 2014, p. 178, itálicos dos autores, acréscimo meu). Nos termos de Indursky (2016), vemos o sujeito-autor retornando sobre o seu escrito e transformando-o em rascunho de um novo texto, ao reabri-lo novamente ao interdiscurso na busca (ilusória) pelo controle das formas e dos sentidos em deriva. Tais retornos são mediados pela sua alienação ao discurso do outro (semelhante) enquanto representante do Outro (tesouro de significantes).

Antes, porém, da alienação, há uma separação do discurso do outro: de início, EMA não aceita o que LIA - sua sobrinha mais velha, já alfabetizada e, portanto, ocupante de uma posição-sujeito identificada à forma-sujeito do que poderíamos chamar de uma FD alfabetizadora - diz-lhe sobre o modo como ele deve registrar graficamente o seu nome próprio. Para LIA, cuja mãe partilha com EMA os dois sobrenomes, estes figuram como pré-construídos cuja forma e cujo sentido lhe são literais e transparentes, de modo que ela "sabe" que eles devem ser separados por espaço em branco. Como um discurso transverso, o discurso do outro (LIA) enquanto representante do Outro (a escrita) atravessa o discurso do sujeito (EMA) e impõe que nele os pré-construídos "Souza” e "Oliveira” sejam 
encadeados de uma dada maneira - e não de outra - na linearidade sintagmática do intradiscurso.

Entretanto, devido à discordância de EMA, é preciso que GIO - o adulto da situação, aparentemente visto por ele como a posição discursiva que simboliza o funcionamento da escrita constituída - intervenha para que a criança opere um deslocamento no interior do reformulável e modifique seu enunciado escrito. Esse deslocamento seguido de reformulação atesta a anterioridade constitutiva do interdiscurso (atrelado ao esquecimento $1^{\mathrm{o}}$, ideológico-inconsciente) em relação à enunciação (vinculada ao esquecimento $\mathrm{n}^{0} 2$, enunciativo), bem como o papel da base linguística como lugar material de realização do discurso enquanto efeito de sentido produzido na interlocução. Afinal, o sujeito do discurso primeiramente se contraidentifica com a FD na qual está se inserindo, separando-se do discurso do outro, mas, em seguida, a ela se identifica ao alienarse a esse discurso e ajustar a grafia de seu nome às prescrições da referida FD.

Essa identificação dá-se mediante um trabalho discursivo do sujeito-autor, que recorta um saber do interdiscurso, linearizando-o no enunciado escrito. Tal saber cultural - que dita a maneira "correta" de delimitar visualmente os grafemas sobre a folha de papel - é, assim, interpretado pela criança e revestido de materialidade linguística em seu enunciado escrito. Esse revestimento se processa por intermédio de uma sintaxe discursiva ( $c f$. INDURSKY, 2016), que sintagmatiza grafemas primeiramente na composição de uma mesma unidade gráfica e, posteriormente, na recomposição dessa unidade em duas outras, separadas pelo branco.

Interdiscurso e enunciação estão, portanto, ligados por "uma relação de dominância que se pode caracterizar dizendo que 'o não afirmado precede e domina o afirmado"” (PÊCHEUX; FUCHS, 2014, p. 178). Nota-se, aqui, também a ordem de sobredeterminação da prática discursiva da escrita, abordada por Indursky (2016), ao traçar o percurso que parte da interpelação ideológica do sujeito como sujeito do seu discurso, passa pela interpretação que ele faz das discursividades e dos saberes provenientes da FD e do interdiscurso e chega à materialização, pela língua e na escrita, desses saberes culturais. Trata-se, pois, 
de "um processo de determinação do sujeito que, por sua vez, determina sua prática da escrita, ou seja, trata-se de um processo complexo que inicia no sujeito e se estende à sua prática discursiva da escrita, sobredeterminando-a" (INDURSKY, 2016, p. 45).

Também a noção de escrita de entremeio, proposta por Zapelini (2016), pode nos ajudar a interpretar a movimentação de sentidos aqui em jogo. Embora a autora circunscreva tal noção aos funcionamentos discursivos que identifica na turma de Educação Infantil que acompanhou em sua pesquisa, podemos estender essa noção à escrita de crianças que, como EMA, já se encontram em processo de alfabetização. O funcionamento discursivo que parece operar nas SDs 1a e 1b é o $F 2$, expresso na fórmula "grafia + ORAL + sentido = texto 1", na medida em que a oralidade constitui com a escrita uma unidade de sentido determinante da produção gráfica da criança. Em outros termos: a alocução falada de EMA com LIA e GIO ( $c f$. SD1a) incide sobre a elaboração de seu enunciado escrito ( $c f$. SD1b), modificando-o.

As SDs 1a e 1b testemunham ainda a centralidade do nome próprio durante a relação inicial da criança com esse outro modo de significar que é o escrever. Conforme Bosco (2006), em estudo sobre aquisição da escrita a partir da perspectiva linguístico-psicanalítica de Cláudia de Lemos, a assinatura cumpre uma função de extrema relevância na estruturação da escrita infantil, tanto em termos linguísticos quanto em termos sociais. Isso porque "Saber escrever o nome significa, aos olhos dos pais e da escola, o primeiro grande triunfo da criança na aquisição da escrita” (BOSCO, 2006, p. 102), sendo na relação da criança com materiais em que consta registrado seu nome que a escrita deste "vai surgindo e se transformando, passando de rabiscos, traçados indiferenciados sobre o papel, para aos poucos ganhar corpo, forma, linearidade e ordem, num percurso que chega a levar entre dois e três anos" (BOSCO, 2006, p. 102). Isso conduz a autora a afastar-se de abordagens referencialistas do nome próprio, que veem nele um reflexo direto do real, como se entre linguagem e mundo uma relação termo a termo houvesse, e a definir o nome próprio enquanto 
um significante que cifra a história de um sujeito; história esta que constitui uma rede de significantes que se apaga a cada emissão do nome, permanecendo, contudo, latente na cadeia. Como significante, condensa um traço - único e distintivo - passado a ele na nomeação, o que permite interpretá-lo, mesmo em suas variâncias (alcunhas, apelidos, etc.), como próprio a um sujeito no Outro. Há, pois, algo da ordem do escrito que nele se inscreve no instante da nomeação - o traço, único e distintivo - e que é retomado a cada menção do nome, tornando possível ler um mesmo no diferente. Cada ato de assinatura do nome coloca em cena, a nosso ver, seu estatuto de cifra - cifra da relação do sujeito com o Outro. (BOSCO, 2006, p. 105, negrito da autora).

A partir da breve análise discursiva aqui efetuada, procuro, na seção final a seguir, lançar um olhar de conjunto para os recortes temático, teórico e analítico em torno dos quais se organiza a presente reflexão.

\section{Considerações (provisoriamente) finais}

O percurso de teorização e análise trilhado permite-me formular as seguintes considerações:

- Quanto aos recortes temático e teórico, a interface por Cláudia de Lemos anunciada entre o campo da aquisição da escrita e a análise do discurso de Michel Pêcheux mostrou-se profícua neste texto, que se inscreve e se escreve na mesma linha do estudo de Zapelini (2016) e de outros que buscam investigar a relação inicial criança-escrita à luz de tal marco teórico. O estabelecimento de diálogos como esse contribui para ambos os lados: no lado dos estudos aquisicionais, amplia ainda mais o leque de teorias que informa o campo e fornece respostas heterogêneas para o heterogêneo fenômeno da inserção da criança na escrita; no lado dos estudos discursivos, enriquece o já vasto repertório de temas convertidos em objetos de pesquisa à luz da perspectiva pecheutiana, o que ratifica a fecundidade teórico-metodológica desta.

- Quanto ao recorte analítico, o exame das SDs aqui operacionalizado dá uma amostra da radical mudança a que somos submetidos quando nos inscrevemos na escrita. Vista desde a ótica discursiva, a chamada aquisição 
da escrita não se reduz a um processo cognitivo de aprendizagem nem a um processo sociointeracional de uso da língua. Trata-se, antes, de um processo de transformação simbólica que, tal como a ideologia (cf. ALTHUSSER, 1980) e a despeito da aparente reflexão "metalinguística” que possa ser associada à alfabetização, é inconsciente e não tem início nem fim ( $c f$. CAPRISTANO, 2007), pois mudamos nossa relação com o escrito a cada nova diferente FD em que nos inserimos e mesmo no interior de uma única FD. Formações discursivas estas que determinam o que e como podemos e devemos escrever, mesmo se, como sujeitos ideologicamente interpelados e inconscientemente afetados que somos, ignoremos tais determinações e nos vejamos como as fontes dos sentidos produzidos por nossos escritos. Nesse processo de constituição subjetiva da criança na aquisição da escrita e de seus deslocamentos no interior do graficamente reformulável, o outro (semelhante letrado) enquanto representante do Outro (escrita como tesouro de significantes) desempenha um papel fundamental e fundante: "Lendo para a criança, interrogando a criança sobre o sentido do que 'escreveu', escrevendo para a criança ler, o alfabetizado" (DE LEMOS, 2009, p. 29, aspas da autora), esse outro "que se oferece ao mesmo tempo como semelhante e como diferente, insere-a no movimento lingüístico-discursivo [sic] da escrita" (DE LEMOS, 2009, p. 29).

Se o aparelho ideológico escolar - sem obviamente ignorar as contribuições (inegáveis) do cognitivismo e do sociointeracionismo - levasse mais em conta a dimensão discursiva da prática da escrita, os índices de letramento de nosso país talvez fossem outros. A esse respeito, finalizo o trabalho ora apresentado com as palavras com que Cláudia de Lemos conclui o texto do qual foi retirada a epígrafe deste:

Gostaria de terminar, trazendo, para a reflexão do leitor, um episódio de que participei mais como observadora perplexa do que como interlocutora. Diante da insistência da mãe de uma criança, sucessivamente reprovada na primeira série do primeiro grau, aceitei "avaliar" a sua escrita. Sem saber muito o que fazer, peço a ela que escreva alguma coisa. Numa impecável letra arredondada, em ortografia correta, ela escreve: "A casa é de Maria". Diante da aparência 
de cartilha dessa escrita, peço então para ela que escreva alguma coisa sobre a irmã. Com a dificuldade, entre várias interrupções, numa letra apertada, ela escreve algo em que, dada a "troca de letras", os problemas de separação de palavras, mal pude reconhecer a frase "Minha irmã bateu ni mim". Mas, só aí, pude perceber sua escrita em movimento em um texto em que ela não se apresentava como excluída, como na frase da cartilha e na letra da professora". (DE LEMOS, 2009, p. 29, aspas da autora). 


\section{Referências}

ALTHUSSER, Louis. Ideologia e aparelhos ideológicos do Estado (Notas para uma investigação). Lisboa: Editora Presença / Martins Fontes, 1980.

BORGES, Sônia Xavier de Almeida. A aquisição da escrita como processo lingüístico. In: LIER-DEVITTO, Maria Francisca; ARANTES, Lúcia. Aquisição, patologias e clínica de linguagem. 1. ed. São Paulo: EDUC, FAPESP, 2006.

BOSCO, Zelma Regina. A errância da letra: o nome próprio na escrita da criança. Sínteses - Revista dos Cursos de Pós-Graduação, Campinas, v. 11, p. 99-107, 2006. Disponível em:

http://revistas.iel.unicamp.br/index.php/sinteses/article/view/163. Acesso em: 19 mai. 2020.

CAPRISTANO, Cristiane Carneiro. Mudanças na trajetória da criança em direção à palavra escrita. 253 f. 2007. Tese de Doutorado (Linguística Aplicada). Instituto de Estudos da Linguagem, Universidade Estadual de Campinas (Unicamp), Campinas, 2007. Disponível em:

http://repositorio.unicamp.br/jspui/handle/REPOSIP/270222. Acesso em: 19 mai. 2020.

DE LEMOS, Cláudia Thereza Guimarães. Sobre a aquisição da escrita: algumas questões. In: ROJO, Roxane (Org.). Alfabetização e letramento: perspectivas linguísticas. 1. ed. 4. reimp. Campinas: Mercado de Letras, 2009.

INDURSKY, Freda. As determinações da prática discursiva da escrita. Desenredo, v. 12, n. 1, p. 30-47, jan./jun. 2016. Disponível em: http://seer.upf.br/index.php/rd/article/view/5954. Acesso em: 19 mai. 2020.

MALDIDIER, Denise. A inquietação do discurso - (re)ler Michel Pêcheux hoje. 1. ed. Campinas: Pontes, 2003.

ORLANDI, Eni Puccinelli. Discurso e texto: formulação e circulação dos sentidos. 3. ed. Campinas: Pontes, 2008.

PÊCHEUX, Michel. Análise automática do discurso. In: GADET, Françoise; HAK, Tony (Orgs.). Por uma análise automática do discurso: uma introdução à obra de Michel Pêcheux. 5ed. Campinas: Editora da UNICAMP, 2014.

PÊCHEUX, Michel. Língua, linguagens, discurso. In: Análise de Discurso: Michel Pêcheux - Textos selecionados por: Eni Puccinelli Orlandi. 4. ed. Campinas: Pontes Editores, 2015. 
PÊCHEUX, Michel; FUCHS, Catherine. A propósito da análise automática do discurso: atualização e perspectivas. In: GADET, Françoise; HAK, Tony (Orgs.). Por uma análise automática do discurso: uma introdução à obra de Michel Pêcheux. 5. ed. Campinas: Editora da UNICAMP, 2014.

PÊCHEUX, Michel. Semântica e discurso: uma crítica à afirmação do óbvio. 5 . ed. Campinas: Editora da Unicamp, 2014.

PÊCHEUX, Michel. A análise de discurso: três épocas. In: GADET, Françoise; HAK, Tony (Orgs.). Por uma análise automática do discurso: uma introdução à obra de Michel Pêcheux. 5. ed. Campinas: Editora da UNICAMP, 2014.

SILVA, Carmem Luci da Costa. A criança na linguagem: enunciação e aquisição. 1. ed. Campinas: Pontes Editores, 2009.

ZAPELINI, Clésia da Silva Mendes. A caminho da escrita: uma análise discursiva no entremeio das produções de crianças na Educação Infantil. $177 \mathrm{f}$. 2016. Tese (Doutorado em Ciências da Linguagem) - Programa de PósGraduação em Ciências da Linguagem, Universidade do Sul de Santa Catarina (UNISUL), Tubarão, 2016. Disponível em:

https://www.riuni.unisul.br/handle/12345/2049. Acesso em: 19 mai. 2020.

Artigo recebido em 19 de maio de 2020 e aceito em 8 de julho de 2020. 